\title{
Methods for neovagina creation in women with Mayer-Rokitansky-Küster- Hauser syndrome for subsequent uterus transplantation
}

\author{
Roman Chmel Jra, ${ }^{\mathrm{a}}$, Zlatko Pastor ${ }^{\mathrm{a}}$, Marta Novackovaa ${ }^{\mathrm{a}}$ Nikoleta Chubanovova ${ }^{\mathrm{a}}$, Roman Chmel ${ }^{\mathrm{a}}$
}

\begin{abstract}
Mayer-Rokitansky-Küster-Hauser syndrome is a rare female congenital anomaly that presents with an inability to have coital sexual intercourse and absolute uterine factor infertility. Both surgical and nonsurgical approaches have been described for the treatment of vaginal agenesis to allow satisfactory coitus. Transplantation of the uterus has the challenge of achieving pregnancy and delivery of her own genetic and biological children in a woman without a natural uterus. Women of reproductive age with a congenital form of absolute uterine factor infertility are considered appropriate recipients of a uterus in the experimental phase of uterus transplantation trials. A neovagina in the normal anatomic position covered by natural non-keratinized mucosa is one of the main assumptions for surgical and reproductive success in transplant recipients. More than 70 uterine transplants have been performed to date, and more than 25 childbirths have been achieved by several research centers in the recipients of a uterus with uterine agenesis. In women with Mayer-Rokitansky-Küster-Hauser syndrome, skin-graft neovagina, Vecchietti's vaginoplasty, and selfdilation using Frank's and Ingram's methods are appropriate techniques to create a neovagina if transplantation of the uterus is intended in the future.
\end{abstract}

Key words: absolute uterine factor infertility, dilation, Mayer-Rokitansky-Küster-Hauser syndrome, neovagina, uterus transplantation, Vecchietti's method

Received: April 25, 2021; Revised: May 23, 2021; Accepted: July 14, 2021; Available online: August 24, 2021

https://doi.org/10.5507/bp.2021.049

(c) 2021 The Authors; https://creativecommons.org/licenses/by/4.0/

${ }^{a}$ Department of Obstetrics and Gynecology, Second Faculty of Medicine, Charles University and Motol University Hospital, Prague, Czech Republic

${ }^{b}$ Faculty of Medicine in Pilsen, Charles University, Pilsen, Czech Republic

Corresponding author: Roman Chmel Jr, e-mail: roman.chmel2@fnmotol.cz

\section{INTRODUCTION}

Mayer-Rokitansky-Küster-Hauser syndrome (MRKHS) is a rare congenital anomaly characterized by agenesis of the uterus and upper two-thirds of the vagina in women with a normal female karyotype. The incidence is estimated to be $1: 4,500$ births in female sex newborns ${ }^{1}$. As the ovaries undergo normal development, women with MRKHS have normal female secondary sexual characteristics. The syndrome is usually revealed only during adolescence, presenting with primary amenorrhea and/or unsuccessful attempts of vaginal intercourse. MRKHS is classified into two clinical types. The typical form (type I) is associated with a symmetrical developmental disorder of the caudal parts of the Müllerian ducts, which means that both the uterus and upper part of the vagina are absent and rudimentary uterine horns are often present, while other organ anomalies are not associated. Together with uterovaginal agenesis, malfunctions in the other organs occur in the atypical form (type II) of MRKHS, particularly in the renal, skeletal, and cardiac systems. The most severe form of type II is represented by Müllerian Renal Cervical Somite (MURCS) syndrome ${ }^{2,3}$.

There are a plethora of techniques to create neovagina in women with MRKHS, but standardized therapy has not yet been established. The optimal neovagina has original anatomic placement and is covered by natural non-keratinized mucosa ${ }^{4}$. In women with MRKHS, recent advances in assisted reproductive techniques have helped achieve genetic motherhood by either gestational surrogacy or uterus transplantation (UTx), which, being in an experimental phase, may fulfill maternal desires in some women with both congenital and acquired absolute uterine factor infertility (AUFI). The first Czech child after UTx from a deceased donor was born in August 2019, followed by a second childbirth in November 2019 from the uterus of the newborn's grandmother ${ }^{5}$. The presence of a formed vagina is considered to be an a priori condition for subsequent UTx in women with AUFI.

The primary aim of the treatment of vaginal agenesis is to create neovagina that is functional, both in terms of its length and sexual satisfaction in the couple, and subsequently, to increase woman's overall quality of life and well-being. Based on our recent research on sexuality and interest in reproductive options in women with MRKHS $\left(\right.$ ref. $\left.{ }^{4,6}\right)$, the objective of this study was to describe the most common methods of neovagina creation for different aspects of subsequent UTx, particularly with respect to post-transplant vaginal stenosis of the uterine-vaginal anastomosis and reproductive success. 


\section{METHODS}

This study is based on literature review of nonsurgical and surgical methods for neovagina creation with respect to subsequent uterus transplantation using the Web of Science, Google Scholar and Medline databases with keywords: absolute uterine infertility factor, Mayer-Rokitansky-Küster-Hauser syndrome, neovagina, uterus transplantation. The analysis of the literature was performed in context with the authors' own long-term experience in the treatment of women with MRKHS, particularly regarding methods of neovagina creation and experimental uterus transplantation.

\section{RESULTS}

\section{Nonsurgical treatment}

As the primary therapeutic goal in women with vaginal agenesis is to ensure normal sexual intercourse by creating an anatomically appropriate and sexually functional neovagina, the decision regarding the timing and initiation of treatment for neovagina creation should be preceded by detailed psychological and sexological examinations. The method of neovaginal formation should be offered only to psychologically and emotionally mature adolescents or young women willing to begin vaginal intercourse immediately after the treatment.

In MRKHS women with only partial vaginal agenesis, attempts at sexual intercourse affects the formation of vagina in terms of length and width. However, if the depth of the vaginal dimple is insufficient, dilation therapy is recommended. A success rate of $95 \%$ has been demonstrated in a study of 245 women with MRKHS using vaginal dilators?.

The most common dilation therapy is Frank's method, which was first described in 1938, and neovagina was created using dilators of gradually increasing length and width ${ }^{8}$. This method is based on the effect of local pressure on the vaginal dimple. To achieve an adequate effect, self-dilation should sustain for at least $2 \mathrm{~h}$ daily. After approximately 6 months of dilation, sufficient functional dimensions of the vagina are usually achieved. Frank's dilation method is lengthy and should be utilized by highly cooperative patients. This nonsurgical method provides the optimal length for neovagina, and therefore, may be an optimal technique for subsequent UTx. Moreover, candidates' level of compliance is assessed before transplantation using self-dilation, as a high level of compliance is necessary to initiate the complex long-term treatment of AUFI using UTx; this is important in the experimental phase, when several aspects are unknown and are currently being researched in human trials.

Ingram's method was introduced in the 1980s as an alternative to Frank's technique, which uses a woman's own body weight together with the effect of gravity'. The dilation is performed by the patient sitting in a slight forward bend on a bicycle seat, thereby creating pressure on the perineum. To succeed, multiple sessions of $30 \mathrm{~min}$ every day are required.
The advantages of both the dilation techniques include minimal morbidity and a low rate of complications. The treatment itself is patient-driven and relatively easy to perform; and, it is performed in an outpatient setting, with a favorable cost-benefit rate.

Patients' non-compliance due to the duration of therapy, the risk of accidental urethral dilation, and postdilation vaginal prolapse are few potential disadvantages of both nonsurgical methods of neovagina creation. Moreover, the treatment regimen can psychologically affect the women, including shame and embarrassment, as the therapy reminds them of their congenital handicap ${ }^{10}$. In contrast, an important advantage of this technique is the avoidance of intraabdominal pelvic adhesions, such as intestinal vaginoplasty, that can arise frequently after surgical methods and can be an obstacle to successful UTx.

If nonsurgical methods fail, surgical creation of neovagina is still possible. In such cases, it is advantageous that the patients undergoing dilation procedures should be compliant with mandatory dilation after surgical creation of neovagina. However, the criteria for failed dilation are not defined in terms of overall duration of the treatment and optimal timing of the onset of dilation.

Moreover, the frequency of dilation is more important than the overall duration of therapy. Three vaginal dilations daily for 10-30 min can help achieve anatomical success faster than that with one prolonged dilation daily; however, the functional success rate does not differ ${ }^{11}$. The length of the dilated neovagina usually does not correlate with the onset of coital sex, but gently penetrative vaginal intercourse can accelerate the dilation of the neovagina and should begin when the patient is ready.

\section{Surgical treatment}

The surgical approach is preferred when the dilation of the neovagina fails. There are two surgical techniques for neovagina creation in women with MRKHS. The first technique is a traction method, such as the Vecchietti's procedure, while the second comprises several graftbased procedures using various types of grafts to form the neovagina. There is no consensus on the preferred surgical method; however, patients should be referred to centers specialized in reconstructive neovaginal surgery. Laparoscopic-assisted techniques are currently more acceptable than laparotomy procedures, particularly due to their minimally invasive nature and cosmetic reasons. Robot-assisted laparoscopy also ensures safe surgery with minimal risk of postoperative complications ${ }^{12}$. Pros and cons of each method of neovagina creation are summarized in Table 1.

\section{Vecchietti's vaginoplasty}

This type of vaginoplasty was originally described by Vecchietti in $1965\left(\right.$ ref. $\left.^{13}\right)$. It is probably the most popular technique for surgical creation of neovagina in Europe. It is considered a surgical version of the Frank's method, as it combines both surgical and dilation approaches. In 1994, laparoscopic modification of this procedure was described by supporters of Vecchietti's technique ${ }^{14}$. 
Table 1. Pros and cons of different neovagina creation methods in relation to subsequent uterus transplantation.

\begin{tabular}{|c|c|c|}
\hline Method of neovagina creation & Pros & Cons \\
\hline Dilation & $\begin{array}{l}\text { Normal vaginal epithelium } \\
\text { Minimal morbidity } \\
\text { Low rate of complications } \\
\text { Patient-driven treatment } \\
\text { Relatively easy to perform in an outpatient } \\
\text { setting } \\
\text { Favorable cost-benefit rate } \\
\text { Avoidance of intraabdominal pelvic adhesions } \\
\text { (important for subsequent uterus transplant) }\end{array}$ & $\begin{array}{l}\text { Non-compliance due to the duration of } \\
\text { therapy } \\
\text { Painful dilation } \\
\text { Accidental urethral dilation } \\
\text { Post-dilation vaginal prolapse }\end{array}$ \\
\hline Vecchietti's vaginoplasty & $\begin{array}{l}\text { Normal vaginal epithelium } \\
\text { No postoperative intraabdominal adhesions } \\
\text { Presence of a normal vaginal microbiome } \\
\text { Relatively short duration of postoperative } \\
\text { dilation } \\
\text { High anatomical success rate }\end{array}$ & $\begin{array}{l}\text { Risk of intraoperative injury to the bladder } \\
\text { and rectum }\end{array}$ \\
\hline Abbe-McIndoe's vaginoplasty & $\begin{array}{l}\text { No abdominal surgery } \\
\text { Optimal length of neovagina achieved }\end{array}$ & $\begin{array}{l}\text { No natural vaginal epithelium } \\
\text { Cosmetic consequences after skin grafting } \\
\text { Vaginal infection } \\
\text { Intravaginal hair growth }\end{array}$ \\
\hline Intestinal vaginoplasty & $\begin{array}{l}\text { Quality of lubrication } \\
\text { Highest length of neovagina }\end{array}$ & $\begin{array}{l}\text { Intraabdominal pelvic adhesions (crucial } \\
\text { obstacle for subsequent uterus transplant) } \\
\text { Highly invasive method } \\
\text { Stenosis of the vaginal introitus requiring } \\
\text { dilation } \\
\text { Vaginal discharge }\end{array}$ \\
\hline Davydov's method & Optimal size of neovagina & $\begin{array}{l}\text { Postoperative deep pelvis adhesions } \\
\text { Vaginal discharge } \\
\text { Risk of vaginal stenosis }\end{array}$ \\
\hline Williams's vaginoplasty & $\begin{array}{l}\text { Simple procedure } \\
\text { Optimal surgical effect }\end{array}$ & $\begin{array}{l}\text { Long-term postoperative dilation } \\
\text { Inappropriate axis of neovagina } \\
\text { Risk of intravaginal hair growth and scarring }\end{array}$ \\
\hline
\end{tabular}

The surgical method involves creation of neovagina by gradual stretching. The traction device is placed suprapubically and then connected to the threads introduced transperineally, crossing the vesicorectal space. Under laparoscopic control, Vecchietti's thread-bearing needle is introduced and passed subperitoneally until reaching the vesicorectal space. An olive-like bead is positioned with threads on the perineal side of the vaginal dimple, and the opposite side of the Vecchietti's needle is brought back with two threads through the abdominal wall. Threads are attached to the traction device on the anterior abdominal wall. A cylinder-shaped phantom connected to the traction mechanism is gradually tightened, causing an invagination in the vesicorectal space to grow both in length and width. The integrity of the bladder and rectum should be checked immediately with cystoscopy and rectoscopy control. The traction should be applied sensitively because excessive traction can cause necrosis of the vaginal epithelium. The Vecchietti supporting device is usually removed when the neovagina is $7-8 \mathrm{~cm}$ long. Thereafter, the women are instructed to perform dilation for several hours every day during the first postoperative month. Estrogen-based vaginal creams are applied to stimulate vaginal epithelialization. Intensive use of dilators usually ceases one month after surgery, and vaginal sexual intercourse is allowed when the neovagina is covered by normal vaginal mucosa that is essential for UTx; also, the presence of a normal vaginal microbiome is considered important, particularly for the reproductive success of the treatment of AUFI using UTx together with assisted reproductive technologies.

The Vecchietti procedure is effective and safe, with a low complication rate ${ }^{4,15}$. Based on the principles of the surgery and due to previous experience with UTx in recipients with Vecchietti-based neovagina in the Czech Republic and Germany, Vecchietti's vaginoplasty is appropriate for the surgical and reproductive success of subsequent UTx ( ref. $^{16,17}$ ).

\section{Abbe-McIndoe's vaginoplasty and its modifications}

This surgical method was pioneered by Abbe in 1898 , but was described by McIndoe in 1938. It requires creation of a tunnel in the rectovesical space. Tissue dissection is performed between the urethra and urinary bladder anteriorly and rectum posteriorly with the Douglas pouch being the upper and posterior bound. A split-thickness skin graft is placed on a vaginal stent with the dermal part facing outside and inserted into the dissected rectovesical 
space. The margins of the skin graft are sewn to the prepared perineal margins. This method requires no transabdominal approach. A vaginal stent with the channel inside helps to clean the neovagina daily. Approximately 10 days postoperatively, the vaginal stent is removed. However, as an autologous skin graft is needed, McIndoe's vaginoplasty leaves a scar on the anterior part of the thigh or gluteal region. Moreover, the risk of neovaginal squamous cell carcinoma has been reported ${ }^{18}$. The vaginal mold has to stay intact for approximately three months, and later, patients are advised to use the mold during the night for the following three months. Six months postoperatively, the mold has to be inserted three times weekly until the patient can have regular sexual intercourse. A cream with protein extract can be applied to enhance epithelialization of the neovagina. The McIndoe's technique has a risk of vaginal infection and requires skin grafting, and thus, may not be optimal for neovagina creation before the intended UTx, although reproductive success in recipients of the transplanted uterus with neovagina has been achieved ${ }^{19}$.

Different modifications of the McIndoe's technique have been described till date. The use of amniotic membranes is a promising and immunologically safe alternative, with no rejection problems ${ }^{20}$. An innovative modification of the McIndoe's technique using autologous in vitro cultured vaginal tissue was described in 2015 (ref. ${ }^{21}$ ). Using this method, patients undergo mucosal biopsy from the vaginal vestibule before treatment. Further, the vestibular cells are extracted by enzymatic dissociation, placed on a special medium, and cultured in vitro. Thereafter, mucosal tissue development requires 2-3 weeks. The dilation of the neovagina begins 10 days postoperatively. Moreover, as autologous tissue is used, there is no risk of rejection, and women with this type of neovagina can have a satisfactory sexual life because of the feeling that their vagina is made up of own vaginal tissue ${ }^{22}$.

\section{Intestinal vaginoplasty}

Using an open or laparoscopic abdominal-perineal surgical approach, an approximately $15 \mathrm{~cm}$ segment of the sigmoid colon or small intestine is mobilized on the vascular pedicle, preserving the blood supply. The continuity of the bowel is restored using end-to-end anastomosis. The proximal end of the graft is closed, and the distal part is moved to the perineum after dissection of the rectovesical space. The lumen of the newly created neovagina is filled with gauze for several days postoperatively. A noticeable advantage of this method is that it does not require longterm regular vaginal dilation. However, stenosis of the muco-cutaneous junction, decreased quality of sexual life due to excessive mucous neovaginal discharge, ulcerative colitis of the intestinal graft, and occurrence of squamous cell carcinoma or adenocarcinoma have been reported ${ }^{23-25}$. Moreover, due to significant morbidity (particularly neovaginal stenosis and infection due to intestinal bacterial flora), intestinal vaginoplasty is considered inappropriate in women with MRKHS willing to undergo UTx in the future. Therefore, this method is currently reserved for patients with complex anomalies of the genitourinary tract.

\section{Davydov's method}

This surgical procedure uses the patient's peritoneum as the lining of the neovagina ${ }^{26}$. Similar to the other techniques, the vesicorectal space is dissected until the peritoneum is reached. The laparoscopically mobilized peritoneal sac is opened, pulled downward through the preformed vesicorectal pouch, and then stitched circumferentially with the vaginal edges. The apex of the vagina is created with the suture of the peritoneum and large bowel serosa. A vaginal mold is inserted for 6 weeks, followed by daily vaginal dilation for 30 min till the woman is sexually active. Davydov's technique using laparoscopic approach is effective and safe when performed by specialized surgeons ${ }^{27,28}$. However, when the neovagina creation fails postoperatively, deep pelvis adhesions may prevent both reoperation to recreate the neovagina and successful transplantation of the uterus. Therefore, this operation could be unsuitable in women with MRKHS interested in subsequent UTx.

\section{Williams's vaginoplasty}

This surgical technique is simple to perform and starts with a U-shaped incision in the skin across the perineum till the medial side of the labia to the level of the external meatus of the urethra ${ }^{29}$. The tissue is mobilized, and the first layer of stitches is placed between the inner skin margins. To support the neovagina, a second layer of stitches is performed between the subcutaneous fat and perineal muscles. At the end of the procedure, an approximately $5 \mathrm{~cm}$ neovaginal channel is created, and the external skin of the labia majora is sutured to form a short vertical vagina. Long-term dilation is necessary after the surgery. Optimal surgical success can be achieved, particularly in women with an impressionable vaginal dimple. However, an inappropriate axis of neovagina, together with the risk of vaginal hair growth and scarring, are the main disadvantages that hinder subsequent UTx.

\section{DISCUSSION}

The encouraging results of the first Swedish human UTx trial with the first transplant performed in 2012 and the first child born from the transplanted uterus subsequently in 2014 brought hope to many women with MRKHS worldwide to fulfill their maternal desires ${ }^{19,30}$. The first promising results of the above experimental UTX trial raised new issues, including suitable modalities for the neovagina creation in women with MRKHS as potential candidates for subsequent UTx. It is difficult to define the success of the neovagina creation therapy, but it can be considered for anatomical and functional satisfaction with surgical and nonsurgical modalities. Moreover, the creation of the neovagina primarily allows coital sex, although it also helps to improve the feeling of femininity and quality of life in women with uterovaginal agenesis. A Czech study on sexuality in women with MRKHS after Vecchietti's vaginoplasty revealed that $97 \%$ of their male sexual partners failed to recognize that they had 
a surgically created neovagina ${ }^{4}$. This could be a sign of overall successful therapy. Therefore, as there is no defined minimal length of the neovagina associated with functional satisfaction in women with MRKHS, success should be simply defined as the creation of neovagina allowing comfortable sexual activity. According to Masters and Johnson, the nulliparous vagina is $7-8 \mathrm{~cm}$ from the introitus to the posterior vaginal fornix when not stimulated, but it may lengthen by $3-4 \mathrm{~cm}$ during sexual arousal ${ }^{4}$. Based on preliminary results of UTx studies, the length of the neovagina in UTx candidates is an important aspect of both surgical and reproductive success.

A holistic approach to the management of women with MRKHS is essential. While anatomical correction using any of the above techniques is an important aspect of the therapy, psychological and sexological support is crucial to improve the emotional well-being and quality of life in women with MRKHS and newly created neovagina. Therefore, women with this rare congenital anomaly should be treated at specialized multidisciplinary centers.

Approximately 75 UTx have been performed worldwide, but no trials have been conducted to compare the suitability of the different methods of neovagina creation in women with MRKHS for surgical and reproductive results of the subsequent UTx (ref. ${ }^{31}$ ). The first review on this topic focused on anatomical criteria essential for the success of subsequent UTx was reported by German researchers in 2019 (ref. ${ }^{32}$ ). As research activities in the field of UTx are accelerating rapidly and more than 25 children have been born after UTx in several centers worldwide, the criteria for the optimal method of neovagina creation in potential recipients of the uterus for surgical and reproductive success should be studied continuously.

The foremost UTx from a living donor in Saudi Arabia was performed in a woman with her own vagina after hysterectomy because of the life-threatening intrapartum hemorrhage ${ }^{33}$, but the absolute majority of the further uterine transplants were performed in women with congenital absence of the uterus and vagina. The second UTx from a nulliparous deceased donor was performed in a young woman with MRKHS in Turkey. The recipient of the uterus had the neovagina created using a free jejunum segment, and she experienced several missed abortions without final reproductive success ${ }^{34}$. The origin of the neovagina was unlikely to be the reason for missed abortions, although this speculation lacks evidence. Some Czech and German recipients of transplanted uterus with MRKHS had the neovagina created using surgical techniques $^{16,17}$, whereas in those at the other UTx centers, such as Cleveland and Dallas, USA, the neovagina was created exclusively by self-dilation ${ }^{35,36}$. Based on the initial Czech UTx research regarding both sexuality and interest in UTx in a group of women with MRKHS with surgically created neovagina using the laparoscopic Vecchietti method ${ }^{4,6}$, the gynecological requirements for the forthcoming UTx study were vaginal length of at least $7 \mathrm{~cm}$, natural vaginal axis, and normal vaginal epithelium. Finally, in the Czech group of 10 recipients with transplanted uterus, a total of six women underwent laparoscopic-assisted Vecchietti- based neovagina creation, while another three had their own vagina, and only one underwent a self-dilated neovagina creation using the Ingram's method ${ }^{5}$. Two recipients of the Vecchietti's neovagina lost their uteri early post-transplant due to thrombosis of the graft vessels. In one recipient with her own vagina, early post-transplant herpes simplex virus infection of the graft caused destruction of the uterine cavity and subsequent hysterectomy ${ }^{16}$. Clinically significant stenosis of the uterine-vaginal anastomosis was confirmed early postoperatively in four out of seven Czech recipients of functional transplanted uteri. However, only one recipient with stenosis had surgically created neovagina while two had their own vaginas, and one self-dilated neovagina ${ }^{5}$. Based on this experience in the Czech women, no specific type of vagina is a risk factor for posttransplant vaginal stenosis formation. Therefore, we can speculate that the stenosis of the uterine-vaginal anastomosis is associated with disproportion between the large cervix of the donor's uterus and narrow vaginal/neovaginal vault of the recipient ${ }^{16}$.

Similar to the Czech approach, the German research group from Tübingen selected potential recipients for UTx from the MRKHS candidates with self-dilation or Vecchietti-based neovagina creation. In the German group of recipients of the uterus, three out of four had neovagina created surgically and only one by self-dilation. Posttransplant stenosis of the uterine-vaginal anastomosis, which could be an obstacle for both posttransplant cervical biopsies to control histopathological signs of subclinical rejection and non-traumatic introduction of embryo transfer catheter to the uterine cavity have not been reported by a German group ${ }^{17}$.

The recipients of uteri from living donors in the first human UTx trial conducted in Gothenburg, Sweden, had nonsurgically (self-dilation using Frank's method) and surgically (particularly skin-graft method) created neovagina, but no early stenosis of the graft-to-vagina anastomosis was described in this study ${ }^{19}$. However, in case of the first childbirth after robot-assisted uterus procurement from a living donor in the second Swedish UTx trial, the authors confirmed severe posttransplant vaginal constriction with the necessity of surgical correction. This 33-year-old recipient of the uterus had MRKHS and had previously undergone skin-graft neovagina surgery ${ }^{37}$.

The recommendation of the American College of Obstetricians and Gynecologists for neovagina creation in women with MRKHS is based on nonsurgical dilation, and the same approach is also the method of choice in France $^{38}$. This should be the first-line approach, with surgery reserved for patients with unsuccessful dilation therapy or those refusing nonsurgical approach and preferring surgery ${ }^{9}$. Researchers from the United States (Dallas and Cleveland) have experience with uterine transplants in recipients with previously self-dilated neovagina, and both the groups have achieved reproductive success ${ }^{39,40}$. 


\section{CONCLUSION}

Abbe-McIndoe's skin-graft technique, Vecchietti's vaginoplasty, and Frank's and Ingram's self-dilation techniques are appropriate methods of neovagina creation for both surgical and reproductive success of UTX in the treatment of AUFI. However, despite the promising results of experimental UTx studies to date, the primary goal of treatment in women with MRKHS remains achieving satisfactory sexual activity using the selected method for neovagina formation. Moreover, only a few women with MRKHS can anticipate achieving maternity in the future through the complex treatment of AUFI using UTx and assisted reproductive technologies.

\section{Search strategy and selection criteria}

A literature review of nonsurgical and surgical methods for neovagina creation with respect to subsequent uterus transplantation using the Web of Science, Google Scholar and Medline databases with keywords: absolute uterine infertility factor, Mayer-Rokitansky-Küster-Hauser syndrome, neovagina, uterus transplantation, in the context of the authors' own experience with both neovagina creation methods and experimental uterus transplantation.

\section{ABBREVIATIONS}

AUFI, Absolute uterine factor infertility; MRKHS, Mayer-Rokitansky-Küster-Hauser syndrome; UTx, Uterus transplantation.

Acknowledgments: This study was supported by the Ministry of Health, Czech Republic, Conceptual Development of Research Organization, Motol University Hospital, Prague, Czech Republic 00064203.

Author contributions: RCJr, RC: study design, data collection, data analysis, and manuscript writing/editing; ZP, MN, NC: data collection, and manuscript writing/editing. Conflict of interest statement: The authors declare that they have no conflicts of interest regarding the publication of this article.

\section{REFERENCES}

1. Oppelt P, Renner SP, Kellermann A, Brucker S, Hauser GA, Ludwig KS, Strissel PL, Strick R, Wallwiener D, Beckmann MW. Clinical aspects of Mayer-Rokitansky-Kuester-Hauser syndrome: recommendations for clinical diagnosis and staging. Hum Reprod 2006;21(3):792-7.

2. Saravelos SH, Cocksedge KA, Li TC. Prevalence and diagnosis of congenital uterine anomalies in women with reproductive failure: a critical appraisal. Hum Reprod Update 2008;14(5):415-29.

3. Folch M, Pigem I, Konje JC. Müllerian agenesis: etiology, diagnosis, and management. Obstet Gynecol Surv 2000;55(10):644-9.

4. Pastor Z, Froněk J, Nováčková M, Chmel R. Sexual life of women with Mayer-Rokitansky-Küster-Hauser syndrome after laparoscopic Vecchietti vaginoplasty. Sex Med 2017;5(2):e106-13.

5. Chmel R, Novackova M, Pastor Z. Lessons learned from the Czech uterus transplant trial related to surgical technique that may affect reproductive success. Aust N Z J Obstet Gynaecol 2020;60(4):625-7.
6. Chmel R, Novackova M, Pastor Z, Fronek J. The interest of women with Mayer-Rokitansky-Küster-Hauser syndrome and laparoscopic Vecchietti neovagina in uterus transplantation. J Pediatr Adolesc Gynecol 2018;31(5):480-4.

7. Edmonds DK, Rose GL, Lipton MG, Quek J. Mayer-RokitanskyKüster-Hauser syndrome: a review of 245 consecutive cases managed by a multidisciplinary approach with vaginal dilators. Fertil Steril 2012;97(3):686-90.

8. Frank RT. The formation of an artificial vagina without operation. Am J Obstet Gynecol 1938;35(6):1053-5.

9. Ingram JM. The bicycle seat stool in the treatment of vaginal agenesis and stenosis: a preliminary report. Am J Obstet Gynecol 1981;140(8):867-73.

10. Liao L, Doyle J, Crouch NS, Creighton SM. Dilation as treatment for vaginal agenesis and hypoplasia: a pilot exploration of benefits and barriers as perceived by patients. J Obstet Gynaecol 2006;26(2):1448.

11. Callens N, De Cuypere G, De Sutter P, Monstrey S, Weyers S, Hoebeke $\mathrm{P}$, Cools M. An update on surgical and non-surgical treatments for vaginal hypoplasia. Hum Reprod Update 2014;20(5):775-801.

12. Acar O, Sofer L, Dobbs RW, Greenwald DT, Halgrimson WR, Crivellaro $\mathrm{S}$, Kocjancic E. Single port and multiport approaches for robotic vaginoplasty with the Davydov technique. Urology 2020;138:166-73.

13. Vecchietti G. Creation of an artificial vagina in Rokitansky-KüsterHauser syndrome. Attual Ostet Ginecol 1965;11(2):131-47.

14. Fedele L, Busacca M, Candiani M, Vignali M. Laparoscopic creation of a neovagina in Mayer-Rokitansky-Küster-Hauser syndrome by modification of Vecchietti's operation. Am J Obstet Gynecol 1994;171(1):268-9.

15. Brucker SY, Gegusch M, Zubke W, Rall K, Gauwerky JF, Wallwiener $D$. Neovagina creation in vaginal agenesis: development of a new laparoscopic Vecchietti-based procedure and optimized instruments in a prospective comparative interventional study in 101 patients. Fertil Steril 2008;90(5):1940-52.

16. Chmel R, Novackova M, Janousek L, Matecha J, Pastor Z, Maluskova J, Cekal M, Kristek J, Olausson M, Fronek J. Revaluation and lessons learned from the first 9 cases of a Czech uterus transplantation trial: four deceased donor and 5 living donor uterus transplantations. Am J Transplant 2019;19(3):855-64.

17. Brucker SY, Strowitzki T, Taran FA, Rall K, Schöller D, Hoopmann M, Henes M, Guthoff M, Heyne N, Zipfel S, Schäffeler N, Bösmüller H, Fend F, Rosenberger P, Heim E, Wiesing U, Nikolaou K, Fleischer S, Bakchoul T, Poets CF, Goelz R, Wiechers C, Kagan KO, Krämer B, Reisenauer C, Oberlechner E, Hübner S, Abele H, Dahm-Kähler P, Kvarnström N, Brännström M, Nadalin S, Wallwiener D, Königsrainer A. Living-donor uterus transplantation: pre-, intra-, and postoperative parameters relevant to surgical success, pregnancy, and obstetrics with live births. J Clin Med 2020;9(8):2485.

18. Schober JM. Cancer of the neovagina. J Pediatr Urol 2007;3(3):16770.

19. Brännström $M$, Johannesson $L$, Dahm-Kähler $P$, Enskog $A$, Mölne J, Kvarnström N, Diaz-Garcia C, Hanafy A, Lundmark C, Marcickiewicz J, Gäbel M, Groth K, Akouri R, Eklind S, Holgersson J, Tzakis A, Olausson $M$. First clinical uterus transplantation trial: a six-month report. Fertil Steril 2014;101(5):1228-36.

20. Fotopoulou C, Sehouli J, Gehrmann N, Schoenborn I, Lichtenegger W. Functional and anatomic results of amnion vaginoplasty in young women with Mayer-Rokitansky-Küster-Hauser syndrome. Fertil Steril 2010;94(1):317-23.

21. Benedetti Panici P, Maffucci D, Ceccarelli S, Vescarelli E, Perniola G, Muzii L, Marchese C. Autologous in vitro cultured vaginal tissue for vaginoplasty in women with Mayer-Rokitansky-Küster-Hauser syndrome: anatomic and functional results. J Minim Invas Gynecol 2015;22(2):205-11.

22. Nodale C, Vescarelli E, D'Amici S, Maffucci D, Ceccarelli S, Monti M, Benedetti Panici P, Romano F, Angeloni A, Marchese C. Characterization of human vaginal mucosa cells for autologous in vitro cultured vaginal tissue transplantation in patients with MRKH syndrome. BioMed Res Int 2014;2014:201518. doi: $10.1155 / 2014 / 201518$

23. Carrard C, Chevret-Measson M, Lunel A, Raudrant D. Sexuality after sigmoid vaginoplasty in patients with Mayer-Rokitansky-KüsterHauser syndrome. Fertil Steril 2012;97(3):691-6. 
24. Tillem SM, Stock JA, Hanna MK. Vaginal construction in children. J Urol 1998;160(1):186-90.

25. Froese DP, Haggitt RC, Friend WG. Ulcerative colitis in the autotransplanted neovagina. Gastroenterology 1991;100(6):1749-52.

26. Davydov SN, Zhvitiashvili OD. Formation of vagina (colpopoiesis) from peritoneum of Douglas pouch. Acta Chir Plast 1974;16(1):3541.

27. Baruch Y, Nale R, Parma M, Di Fatta S, Fedele L, Candiani M, Salvatore $\mathrm{S}$. Lower urinary tract symptoms in patients with Mayer-RokitanskyKuster-Hauser syndrome after neo-vagina creation by Davydov's procedure. Int Urogynecol J 2020;31(12):2529-33.

28. Vermel M, Wehr M, Schwaab T, Lecointre L, Host A, Faller E, Akladios C, Garbin O. Surgical video tutorial: treatment of congenital vaginal agenesis: laparoscopic modified Davydov in 8 steps. J Minim Invas Gynecol 2021 Feb 6:S1553;4650(21):00083-2. doi: 10.1016/j. jmig.2021.02.003

29. Williams EA. Congenital absence of the vagina: a simple operation for its relief. J Obstet Gynaecol Br Commonw 1964;71:511-2.

30. Brännström $M$, Johannesson $L$, Bokström H, Kvarnström N, Mölne J, Dahm-Kähler P, Enskog A, Milenkovic M, Ekberg J, Diaz-Garcia C, Gäbel M, Hanafy A, Hagberg H, Olausson M, Nilsson L. Livebirth after uterus transplantation. Lancet 2015;385(9968):607-16.

31. Herlin MK, Petersen MB, Brännström M. Mayer-Rokitansky-KüsterHauser (MRKH) syndrome: a comprehensive update. Orphanet J Rare Dis 2020;15(1):214

32. Kölle A, Taran FA, Rall K, Schöller D, Wallwiener D, Brucker SY Neovagina creation methods and their potential impact on subsequent uterus transplantation: a review. BJOG 2019;126(11):1328-35

33. Fageeh W, Raffa $H$, Jabbad $H$, Marzouki A. Transplantation of the human uterus. Int J Gynaecol Obstet 2002;76(3):245-51.

34. Ozkan O, Dogan NU, Ozkan O, Mendilcioglu I, Dogan S, Aydinuraz B, Simsek M. Uterus transplantation: from animal models through the first heart beating pregnancy to the first human live birth. Womens Health (Lond) 2016;12(4):442-9.

35. Testa G, Koon EC, Johannesson L, McKenna GJ, Anthony T, Klintmalm GB, Gunby RT, Warren AM, Putman JM, dePrisco G, Mitchell JM, Wallis $\mathrm{K}$, Olausson M. Living donor uterus transplantation: A single center's observations and lessons learned from early setbacks to technical success. Am J Transplant 2017;17(11):2901-10.

36. Flyckt RL, Farrell RM, Perni UC, Tzakis AG, Falcone T. Deceased donor uterine transplantation. Innovation and adaptation. Obstet Gynecol 2016;128(4):837-42.

37. Brännström $M$, Dahm-Kähler $P$, Kvarnström $N$, Akouri R, Rova K, Olausson M, Groth K, Ekberg J, Enskog A, Sheikhi M, Mölne J, Bokström $\mathrm{H}$. Live birth after robotic-assisted live donor uterus transplantation. Acta Obstet Gynecol Scand 2020;99(9):1222-9.

38. Gauthier T, Lavoue V, Piver P, Aubard Y, Ayoubi JM, Garbin O, Agostini A, Collinet P, Morcel K, Comité d'Étude de la Transplantation Utérine en France. Which neovagina reconstruction procedure for women with Mayer-Rokitansky-Küster-Hauser syndrome in the uterus transplantation era? Editorial from the French Uterus Transplantation Committee (CETUF) of CNGOF. J Gynecol Obstet Hum Reprod 2018;47(4):175-6

39. Testa G, McKenna GJ, Gunby RT Jr, Anthony T, Koon EC, Warren AM, Putman JM, Zhang $L$, dePrisco G, Mitchell JM, Wallis K, Klintmalm GB, Olausson $M$, Johannesson L. First live birth after uterus transplantation in the United States. Am J Transplant 2018;18(5):1270-4.

40. Flyckt R, Falcone T, Quintini C, Perni U, Eghtesad B, Richards EG, Farrell RM, Hashimoto K, Miller C, Ricci S, Ferrando CA, D'Amico G, Maikhor S, Priebe D, Chiesa-Vottero A, Heerema-McKenney A, Mawhorter S, Feldman MK, Tzakis A. First birth from a deceased donor uterus in the United States: from severe graft rejection to successful cesarean delivery. Am J Obstet Gynecol 2020;223(2):143-51. 